19 Robertson D, Tseng C-J, Appalsamy M. Smoking and mechanisms of cardiovascular control. Am Heart f 1988;115:258-63.

20 Hecht SS, Hoffmann D. Tobacco-specific nitrosamines, an important group of carcinogens in tobacco and tobacco smoke. Carcinogenesis 1988;9:875-84.

21 Williams RR, Horm JW. Association of cancer sites with tobacco and alcohol consumption and socioeconomic status of patients: interview study from the consumption and socioeconomic status of patients. interview stud

22 West $\mathrm{R}$, Krafona $\mathrm{K}$. Oral tobacco: prevalence, health risks, dependence potential and public policy. Br 7 Addict 1990;85:1097-8.

3 Venitt $S$. The dubious evidence for smokeless tobacco. Br 7 Addict 1990;85: 1100-1

24 Russell MAH, Jarvis MJ, West RJ, Feyerabend C. Buccal absorption of nicotine from smokeless tobacco sachets. Lancet 1985;ii: 1370 .

25 Benowitz NL, Porchet H, Sheiner L, Jacob P IIIrd. Nicotine absorption and cardiovascular effects with smokeless tobacco use: comparison with cigarettes and nicotine gum. Clin Pharmacol Ther 1988;44:23-8.

26 Hatsukami DK, Gust SW, Keenan RM. Physiologic and subjective changes from smokeless tobacco withdrawal. Clin Pharmacol Ther 1987;41:103-7.

Ernster VL. Advertising and promotion of smokeless tobacco products. National Institute of Cancer Monographs 1989;8:87-94.

28 Glover ED, Laflin M, Edwards SW. Age of initiation and switching patterns between smokeless tobacco and cigarettes among college students in the United States. Am f Public Health 1989;79:207-8.

29 Eliasson . M, Lundblad D, Hägg E. Cardiovascular risk factors in young snuffusers and smokers. F Intern Med 1991;230:17-22.

30 Schroeder $\mathrm{KL}$, Chen MS. Smokeless tobacco and blood pressure. N Engl F Med 1985;312:919-20.

31 Bolinder G. Även snusning innebär en uppenbar hälsorisk. [The use of snuff is a genuine risk to health]. Läkartidningen 1988;85:1248-51.

32 Stegmayr B, Asplund K, Johansson I. Rökning, snusning och antioxidantia. En befolkningsstudie hos medelålders män [Smoking, snuffing and antioxidants. A population study of middle-aged men]. Hygiea 1991;100:252

33 McGill HC Jr. The cardiovascular pathology of smoking. Am Hear $f$ 1988;115:250-7

34 Brockie RE, Shafer DR, Huber GL. Tobacco and coronary heart disease: risk factors, mechanisms of disease, and risk modification. Semin Resp Med 1990;11:5-35

35 Stavenow L, Pessah-Rasmussen H. Effects of polycyclic aromatic hydrocarbons on proliferation, collagen secretion and viability of arterial smooth muscle cells in culture. Artery 1988;15:94-108.

(Accepted 2 October 1992)

\title{
Risk of schizophrenia in adults born after obstetric complications and their association with early onset of illness: a controlled study
}

\author{
Eadbhard O'Callaghan, Tessa Gibson, Hubert A Colohan, Peter Buckley, David G Walshe, \\ Conall Larkin, John L Waddington
}

\section{Abstract}

Objective-To determine whether obstetric complications occur to excess in the early histories of individuals who go on to develop schizophrenia when compared with controls, and to seek clinical correlates of any such excess.

Design-Contemporaneous maternity hospital records were identified and extracted verbatim, and these extracts evaluated for obstetric complications by two independent assessors who were blind to subjects' status.

Subjects -65 patients having an ICD-9 diagnosis of schizophrenia, the records of the previous same sex live birth being deemed to be those of a control subject.

Main outcome measure-Presence of one or more obstetric complications recorded in maternity notes of patients and controls.

Results-When two recognised scales for specifying obstetric complications were used the patients with schizophrenia were significantly more likely than controls to have experienced at least one obstetric complication (odds ratio $2 \cdot 44,95 \%$

St John of God Psychiatric Services, Blackrock, Co Dublin, Ireland Eadbhard O'Callaghan, consultant psychiatrist

Tessa Gibson, research coodinator

Hubert A Colohan, registrar in psychiatry

Peter Buckley, research

fellow

David G Walshe, registrar in psychiatry

Conall Larkin, consultant psychiatrist

Royal College of Surgeons in Ireland, Dublin 2

John L Waddington,

professor of neuroscience

Correspondence to: Dr E O'Callaghan, Cluain Mhuire Family Centre, Blackrock, Co Dublin, Ireland.
The personal, social, and economic consequences of schizophrenia make it perhaps the most serious of all psychiatric disorders and are a public health problem of major significance. Though the aetiology of this illness remains obscure, recent evidence continues to point not to the period immediately before the onset of psychotic symptoms, typically in the late teens or $20 \mathrm{~s}$, but rather to considerably earlier events. ${ }^{1}$ The neurodevelopmental hypothesis of schizophrenia contends that in fetal or immediate postnatal life the establishment of fundamental aspects of cerebral structure and function is subtly but critically disrupted. Diagnostic symptoms of the disorder are then posited to emerge some two decades later only on the full maturation of other physiological systems that are necessary for expressing the consequences of this early developmental perturbation. ${ }^{2}$

One element of this hypothesis is evidence that patients with schizophrenia may be more likely than other individuals to have experienced a problematic gestation or delivery and the attendant presumption that such obstetric complications might be one source of early cerebral insult. Were this to be the case the significance of such a putative course of events would be compounded by its evident implications for prophylaxis in terms of further improvements in obstetric and perinatal care. However, existing publications on the issue, ${ }^{4-12}$ though provocative, are far from conclusive and are open to several serious methodological criticisms. ${ }^{113}$ For example, widespread reliance on maternal recall as a retrospective source of information on obstetric complications has been considered prone to both inexactitude and artefact, though our own study $^{14}$ indicated it to be of considerably greater validity than had been recognised. Conversely, though "high risk" studies have utilised birth records, all of the subjects' mothers suffered from schizophrenia, so that it may not be possible to generalise to a typical patient population. The use in one study of the maternity records of a modest number of schizophrenic patients was confounded by the use of comparable records only for their "well" siblings, with attendant problems of generalisation to the population at large. ${ }^{12}$

Done and colleagues sought to identify psychiatric morbidity in a population for whom birth histories had been obtained in the 1958 British perinatal mortality survey. They found no evidence that "factors predicting perinatal mortality contribute significantly to causation of schizophrenic illness" among 57 patients and on that basis concluded that obstetric complica-

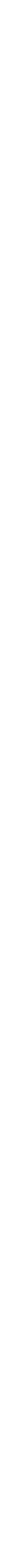


tions bore no aetiological relevance to schizophrenia. ${ }^{13}$ Their negative results could be influential in relation to a fundamental issue in contemporary schizophrenia research but have themselves been the subject of methodological and conceptual criticism. ${ }^{15}$ More pertinently, our own, positive results from an extensive controlled study of obstetric complications in schizophrenia, using blind evaluation of Irish maternity records, are in marked contradiction and seriously challenge these conclusions.

\section{Subjects and methods}

By using the database of the St John of God Hospital, Co Dublin, 616 patients admitted thereto between 1982 and 1986 and having a diagnosis of schizophrenia according to the ICD- ${ }^{17}$ were identified with a view to seeking in either of two Dublin maternity hospitals (National Maternity and Rotunda Hospitals) their biological mothers' records in relation to her pregnancy with and delivery of that patient. It proved possible to locate such records relating to 65 patients. The records relating to the previous same sex live birth at that hospital were also located and deemed to be those of a matched control.

Obstetric complications were defined conventionally as deviations from an expected course during pregnancy, labour, delivery, and the early neonatal period before discharge from the obstetric ward. ${ }^{10}$ Maternal demographic and obstetric data pertaining to each patient and control were extracted verbatim from the records. The information entered therein included socioeconomic group ${ }^{18}$ (not available for 24 controls and 22 patients); parity (not available for one control); previous obstetric history; gestational age of present pregnancy; any complication(s) that may have occurred before and during labour; type of delivery; and weight and general health of the baby at birth. These data were then randomised and evaluated blindly by two of us (EO'C and HAC) independently, using each of the established obstetric complication scales of Lewis et $a l^{19}$ (for this study scale I, which specifies obstetric events as "definite" complications or as "equivocal"that is, a less well specified description of a definite complication) and of Parnas and colleagues ${ }^{10}$ (scale II, which defines the number of specified complications, a severity score as the weight of the single most severe complication described, and a total score as the sum of all individual weighted scores).

There was only one instance of disagreement, relating to the use of scale I in a patient, which was resolved by consensus in the conservative direction and

TABLE I-Obstetric and demographic characteristics of schizophrenic patients and controls. Figures are means (SD) and frequencies

\begin{tabular}{|c|c|c|c|}
\hline & Controls & Patients & $\mathrm{p}$ Value \\
\hline No (male/female) & $65(35,30)$ & $65(35,30)$ & \\
\hline Age (years) & $34 \cdot 7(8 \cdot 9)$ & $34 \cdot 7(8 \cdot 9)$ & \\
\hline Scale I: obstetric complications present & 11 & 24 & $0.03^{\star}$ \\
\hline \multicolumn{4}{|l|}{ Scale II: } \\
\hline No of complications & $0.4(0.6)$ & $0.7(0.9)$ & $0.02 \dagger$ \\
\hline Severity of complications & $0.4(0.8)$ & $0.8(1.2)$ & $0.03 t$ \\
\hline Total complications score & $0.5(0.9)$ & $1 \cdot 1(1 \cdot 6)$ & $0.01 t$ \\
\hline Fetal distress & 0 & 5 & $0.06 \ddagger$ \\
\hline Maternal age (years) & $31 \cdot 1(6 \cdot 1)$ & $30 \cdot 2(7 \cdot 2)$ & $0.36 \$$ \\
\hline \multicolumn{4}{|l|}{ Socioeconomic group|: } \\
\hline Upper & 3 & 5 & \\
\hline Middle & 14 & 23 & $0.04 \dagger$ \\
\hline Lower & 24 & 15 & \\
\hline Previous miscarriages & 10 & 10 & $1 \cdot 00^{\star}$ \\
\hline \multicolumn{4}{|l|}{ Parity||: } \\
\hline First & 14 & 21 & \\
\hline Second-fourth & 30 & 28 & $0 \cdot 26 \dagger$ \\
\hline Fifth or more & 20 & 16 & \\
\hline \multicolumn{4}{|l|}{ Gestation: } \\
\hline Premature & 1 & 1 & \\
\hline Term & 63 & 58 & $0.08 \dagger$ \\
\hline Postmature & 1 & 6 & \\
\hline Birth weight $(\mathrm{g})$ & $3235(579)$ & $3356(493)$ & $0.36 \$$ \\
\hline
\end{tabular}

$\overline{\star N c N e m a r}$ 's test. †Wilcoxon’s test. $¥$ Fisher’s exact probability test. §Paired $t$ test. ||Data missing in some cases. against the study hypothesis. As these scales concern primarily absolute information such as weight, duration of labour, or instrumental delivery they provide less scope for the "blind" clinical impression of the midwife recording the delivery. Therefore, where such a clinical opinion was described in the record (for example, "fetal distress") this was deemed to have occurred and was examined independently.

Patient demographic and clinical data, including age at onset of symptoms and any family history of psychiatric disorder, had been collected for a study of the season of birth phenomenon. ${ }^{20}$ These data had been extracted from detailed psychiatric case note review before the collection of obstetric information. A positive family history was defined as a first or second degree relative with schizophrenia or major affective disorder. Such information was not available for three patients.

Statistical analysis-Comparison of patients with controls and of patients with versus those without a history of obstetric complications was by the Wilcoxon test for ordinal data; paired or unpaired Student's $t$ test for continuous data; and the McNemar or $\chi^{2}$ test for categorical data. All p values given are two tailed. Odds ratios for matched and unmatched data were also determined, with associated $95 \%$ confidence intervals. ${ }^{21}$ Data are expressed as frequencies or means (SD).

\section{Results}

As the data concerned contemporaneous maternity records rather than maternal recall we decided to combine "equivocal" with "definite" complications for scale I. On this basis patients with schizophrenia were significantly more likely than controls $(24(37 \%) v$ $11(17 \%)$; odds ratio $2 \cdot 44,95 \%$ confidence interval 1.08 to 6.03 ; McNemar's test: $p=0.03$ ) to have experienced at least one obstetric complication (table I). The data were also analysed by examining equivocal and definite complications independently; 14 patients experienced definite and 10 patients equivocal complications, while six controls experienced definite and five controls equivocal complications (Wilcoxon's test, $\mathrm{p}=0.06$ ). With scale II comparison of patients and controls indicated a significantly greater number $(p=0.02)$ and severity $(p=0.03)$ of and total score $(p=0.01)$ for obstetric complications in the patient group.

The single complication noted to occur to excess in the schizophrenic group was "fetal distress" (five $(8 \%)$ patients $v$ none among controls; Fisher's exact test: $\mathrm{p}=$ $0 \cdot 06)$. Four of the patients but none of the controls were delivered as part of a multiple (twin) birth. Two of the twin pairs were same sex male pairs, and two were dizygotic pairs with one male and one female affected. Restricting statistical analysis to the 61 control-patient pairs remaining after exclusion of these four twin births failed to influence materially the pattern of differences in obstetric complications between patients and controls (scale I: $p=0.12$; scale II: number, $p=0.03$; severity, $p=0.04$; total score, $p=0.02$ ). The birth of six patients but of only one control was postmature $(p=0 \cdot 08)$. Patients were from a higher socioeconomic group than were controls $(p=0.04)$ but did not differ significantly in terms of maternal age, previous miscarriages, parity, or subject's birth weight.

As shown in table II male patients were significantly more likely than female patients to have experienced at least one obstetric complication (18/35 (51\%) v 6/30 $(20 \%)$; odds ratio $4 \cdot 24,95 \%$ confidence interval 1.39 to $12.90 ; \chi^{2}$ test: $p=0.02$ ). This was not so for the control group, in which five males and six females had such a history ( $14 \% v 20 \% ; \chi^{2}$ test: $\left.p=0 \cdot 78\right)$. Patients with and without a history of obstetric complications did not differ significantly in family psychiatric history or 
TABLE II-Characteristics of schizophrenic patients with and without history of obstetric complications by scale I. Figures are means (SD) and frequencies

\begin{tabular}{lccc}
\hline & \multicolumn{2}{c}{ Obstetric complications } \\
\cline { 2 - 3 } & Absent & Present & p Value \\
\hline No (male/female) & $41(17,24)$ & $24(18,6)$ & $0 \cdot 02^{\star}$ \\
Family history & 17 & 15 & $0 \cdot 24^{\star}$ \\
Winter born & 12 & 5 & $0 \cdot 65^{\star}$ \\
Age at onset (years) & $24 \cdot 8(7 \cdot 2)$ & $20 \cdot 1(3 \cdot 8)$ & $0 \cdot 02 \dagger$ \\
Male & $23 \cdot 5(7 \cdot 0)$ & $19 \cdot 2(3 \cdot 1)$ & $0 \cdot 03 \dagger$ \\
Female & $25 \cdot 7(7 \cdot 9)$ & $22 \cdot 7(4 \cdot 8)$ & $0 \cdot 30 \dagger$ \\
\hline
\end{tabular}

${ }^{\star} \chi^{7}$ test. $\dagger t$ Test.

winter (January to March) birth. However, in an exploratory analysis patients who had experienced obstetric complications had a significantly younger age at onset of illness than patients without such a history (mean difference -4.5 years, $95 \%$ confidence interval $-1 \cdot 2$ to $-7 \cdot 8$ years; Student's $t$ test: $p=0 \cdot 02$ ). This was particularly evident in male patients-but, curiously, it also tended to apply to female patients despite their being no more likely than female controls to have experienced obstetric complications.

\section{Discussion}

These findings indicate that obstetric complications are significantly more common in the early histories of individuals who go on to develop schizophrenia than in the histories of those who do not. By means of two widely recognised obstetric scales the blind evaluation of contemporaneous maternity records by two "blind" and independent assessors disclosed a significantly greater frequency and severity of and total score for obstetric complications in the patient group; this is in evident contradiction to the findings of Done and colleagues. ${ }^{1}$

The issue of seeking any relation between a clinical disorder and a putative aetiological factor acting some decades before presents methodological difficulties for all such studies. ${ }^{113}$ Fortunately, the generally low social mobility and established system of maternity care in Ireland has allowed us to circumvent or mitigate some of these. For example, given the sample size and a $1 \%$ lifetime risk of schizophrenia in the general population, the procedure used to generate the control group may have included one or two individuals who also went on to develop this illness. However, any such occurrence(s) would only have lessened the likelihood of identifying the present differences in obstetric history between patients and controls.

All patients were delivered in hospital, and this was rather less common for individuals born before the 1950 s, perhaps suggesting some overrepresentation among older subjects of pregnancies identified as potentially problematic. The matching of each patient to a control birth occurring within hours in the same maternity hospital, however, obviates the influence on study outcome of any such factor. Done and colleagues argued that maternity records "are often unsystematic," yet their own data systematisation entailed excluding certain obstetric factors (see below) in favour only of those primarily perinatal events identified in a regression model as predictive of stillbirth or neonatal death. ${ }^{13}$ The present procedure recruited matched, historical rapporteurs who were, by the very nature of schizophrenia, blind to diagnosis and who proceeded eclectically in accordance with a common hospital policy about record compilation.

Our patient group was from a higher socioeconomic background (based on paternal occupation) than controls. This presumably reflected an admission bias in the participating psychiatric hospital towards patients with private medical insurance, which would tend to act against the study finding of more obstetric complications in the patient group. The increased rate of occurrence of obstetric complications in schizophrenia did not seem related to maternal age or previous obstetric history, despite many complications having some general association with these factors; we think this may be of relevance as it suggests a basis independent of maternal reproductive health. Obstetric complications and winter birth excess also did not seem to be related, though statistical power was not large. Winter birth excess has proved highly reproducible in schizophrenia, ${ }^{20}$ and to our knowledge no such seasonal variation occurs among obstetric complications.

In general, with regard to putative gene-environment interactions we could find no relation between history of obstetric complications and family history of schizophrenia, which was contrary to our previous report. ${ }^{22}$ However, the two studies were quite dissimilar methodologically and had differing "strengths." Our initial study depended on maternal recall for obstetric information but utilised detailed interviews and operational criteria for determining any family history, whereas this study utilised detailed maternity records but depended on psychiatric case notes for specification of any family history. This important issue will be resolved satisfactorily only by a large study of a representative sample employing both contemporaneous maternity records and ascertainment of family history by the family study method. Interestingly, four patients (no controls) were delivered as part of a multiple (twin) birth. Though there is little evidence that schizophrenia is generally more common among twins, there is a single report of an increased rate of schizophrenia among monozygotic twins in whom the cotwin died at a young age. ${ }^{23}$

\section{NATURE OF OBSTETRIC PROBLEMS IN SCHIZOPHRENIA}

As perhaps a first clue to the nature of obstetric complications in schizophrenia a marked sex effect was evident. The excess of such complications was confined essentially to males and may reflect the greater vulnerability of the male fetus and neonate to early adversity..$^{24}$ Furthermore, in an exploratory analysis, having an obstetric history was associated with an earlier age at onset of psychotic illness in affected individuals. We reported a similar finding based on maternal recall of such history, ${ }^{22}$ and it may be the most robust clinical correlate of obstetric complications in schizophrenia ${ }^{1116}$; it was ignored by Done and colleagues. ${ }^{13}$ The phenomenon also seemed to be more evident in males, and these sex differences in obstetric parameters and their clinical correlates may be relevant to the generally younger age at onset of psychosis and poorer outcome in male patients with schizophrenia. ${ }^{25} 26$

However, the fundamental issue remains the nature of obstetric complications in schizophrenia and the direction of causality. Overall, though the patient group was characterised by a general excess of a mixed bag of early, middle, and late pregnancy or perinatal (primarily middle to late pregnancy and perinatal) complications, "fetal distress" was the only individually recorded eventuality to occur to significant excess. Though not an effect of great absolute or statistical magnitude, it may hold a disproportionately larger conceptual message.

Kerwin and Woodhouse ${ }^{15}$ juxtaposed the purported methodological rigour of the study of Done and colleagues $^{13}$ with that study's selection of obstetric variables to be included. It is difficult to understand why fetal distress should have been excluded from their analyses ${ }^{13}$ as it is a leading predictor of postnatal outcome. There is obstetric opinion that fetal distress generally indicates oxygen deprivation and, when present in the absence of any other complication, implies a fetus that has been already compromised in 
some way. ${ }^{27}$ We might speculate on an already compromised neurological system which would impair the ability of such a fetus to play its part in delivery. Therefore, on that basis such obstetric complications may not be of direct aetiological relevance but rather may be the secondary consequences of yet earlier events. In this regard there is strong evidence that perinatal complications such as low birth weight and prematurity are much more common in women who have experienced first trimester vaginal bleeding. ${ }^{28}$ Thus such signs can also be secondary to perhaps unappreciated events acting considerably earlier in pregnancy.

In conclusion, data from a blind controlled study of Irish maternity records indicate a significant excess of obstetric complications in the early histories of schizophrenic patients, particularly males, that are unrelated to maternal demographics and general reproductive health. The data further suggest that obstetric complications are associated with a significantly earlier onset of illness, particularly in male patients. Though our data show that obstetric complications are associated with subsequent schizophrenia, they do not provide evidence of causality. Indeed, obstetric complications themselves may be the consequence of yet earlier genetic or environmental events, or both. It would be regrettable were recent negative findings ${ }^{13}$ to discourage investigators from pursuing further such a potentially fruitful approach to the fundamental issue of the nature of neurodevelopmental disturbance in schizophrenia.

We are grateful to the St John of God Order, the Health Research Board, and the Stanley Foundation for financial support, and to the Masters of the National Maternity and Rotunda hospitals for their kind assistance.

1 Waddington JL, Torrey EF. Schizophrenia, neurodevelopment and disease. Arch Gen Psychiaty 1991;48:271-3.

2 Murray RM, Lewis SW. Is schizophrenia a neurodevelopmental disorder? BM7 1987;295:681-2.

3 Weinberger DR. Implications of normal brain development for the pathogenesis of schizophrenia. Arch Gen Psychiatry 1987;44:660-9.

4 Lane EA, Albee GW. Comparative birth weights of schizophrenics and their siblings. I Psychology 1966;64:227-31

5 Pollack M, Woerner M, Goodman W, Greenberg I. Childhood developmen patterns of hospitalised adult schizophrenic and non-schizophrenic patients and their siblings. Am f Orthopsychiatry 1966;36:510-97.

6 Pollack M, Levenstein S, Klein DF. A three year post-hospital follow-up of adolescent and adult schizophrenics. Am F Orthopsychiatry 1968:38:94-109.
7 Woerner M, Pollack M, Klein DF. Pregnancy and birth complications in psychiatric patients: a comparison of schizophrenic and personality disorder patients with their siblings. Acta Psychiatr Scand 1973;49:712-21

$8 \mathrm{McNeil} \mathrm{TF}$, Kaij L. Obstetric factors in the development of schizophrenia complications in the births of preschizophrenics and in reproduction by schizophrenic patients. In: Wynne LC, Cromwell RL, Matthyssee S, eds. The nature of schizophrenia. New York: Wiley, 1978:401-29.

9 Jacobsen B, Kinney DK. Perinatal complications in adopted and non-adopted schizophrenics and their controls: preliminary results. Acta Psychiatr Scand 1980;62(suppl 285):337-46.

10 Parnas J, Schulsinger F, Teasdale TW, Schulsinger H, Feldman PM, Mednick SA. Perinatal complications and clinical outcome within the Mednick SA. Perinatal complications and clinical ou
schizophrenia spectrum. Br f Psychiatry 1982;140:416-20.

11 Lewis SW, Murray RM. Obstetric complications, neurodevelopmental deviance and risk of schizophrenia. $\mathcal{F}$ Psychiatr Res 1987;21:413-22.

12 Eagles JM, Gibson I, Bremner MH, Clunie F, Ebmeier KP, Smith NC Obstetric complications in DSM-III schizophrenics and their siblings. Lancet 1990;336:1139-41

13 Done DJ, Johnstone EC, Frith CD, Golding J; Shepherd PM, Crow TJ Complications of pregnancy and delivery in relation to psychosis in adult life: data from the British perinatal mortality survey sample. $B M \mathcal{Y}$ 1991;302:1576-80.

14 O'Callaghan E, Larkin C, Waddington JL. Obstetric complications in schizophrenia and the validity of maternal recall. Psychol Med 1990;20 $89-94$.

15 Kerwin R, Woodhouse W. Complications of pregnancy and delivery and psychosis in adult life. BMf 1991;303:188.

16 Lewis S, Stewart A. Complications of pregnancy and delivery and psychosis in adult life. $B M \mathcal{F}$ 1991;303:582.

17 World Health Organisation. Mental disorders: glossary and guide to their classification in accordance with the ninth revision of the international classification of diseases (ICD-9). Geneva: WHO, 1978 .

18 Central Statistics Office. Census '86. Dublin: Government Stationary Office, 1987

19 Lewis SW, Owen MJ, Murray RM. Obstetric complications and schizophrenia: methodology and mechanisms. In: Schulz SC, Tamminga CA, eds. Schizophrenia: scientific progress. New York: Oxford University Press, 1989:56-68.

20 O'Callaghan E, Gibson T, Colohan HA, Walshe D, Buckley P, Larkin C, et al. Season of birth in schizophrenia: evidence for confinement of an excess of winter births to patients without a family history of mental disorder. $\mathrm{Br} f$ Psychiatry 1991;158:764-9.

21 Gardner MJ, Altman DG. Statistics with confidence: confidence intervals and statistical guidelines. London: British Medical Journal, 1989.

22 O'Callaghan E, Larkin C, Kinsella A, Waddington JL. Obstetric complications, the putative familial-sporadic distinction and tardive dyskinesia in schizophrenia. Br $\mathcal{P}$ Psychiatry 1990;157:578-84.

23 Chitkara B, McDonald AM, Reveley AM. Twin birth and adult psychiatric disorder: an examination of the case reports of the Maudsley Hospital. $\mathrm{Br} f$ Psychiatry 1988;152:391-8.

24 O'Callaghan E, Larkin C, Kinsella A, Waddington JL. Familial, obstetric and other clinical correlates of minor physical anomalies in schizophrenia. $A m \mathcal{J}$ Psychiatry 1991;148:479-83.

25 Goldstein JM, Tsuang MT. Gender and schizophrenia. Schizophr Bull 1990;16:179-83

26 Murray RM, O'Callaghan E. The congenital and adult onset schizophrenias: "Kraepelin lost-Kraepelin found." In: Kerr A, ed. Concepts of mental disorder. London: Royal College of Psychiatrists, 1991:48-65.

27 Chamberlain GVP. The fetus, placenta and amniotic fluid. In: Whitfield CR ed. Dewhurst's textbook of obstetrics and gynecology for postgraduates. London: Blackwell, 1987:101-14

28 Williams MA, Mittendorf R, Lieberman E, Monson RR. Adverse infan outcomes associated with first-trimester vaginal bleeding. Obstet Gynecol 1991;78:14-8.

(Accepted 11 September 1992)

\section{ONE HUNDRED YEARS AGO}

\section{PUBLIC CONVENIENCES FOR WOMEN.}

The long suffering of women from want of free latrine accommodation in places of public resort, streets of cities, railway stations, etc., seems at length to have attracted such sustained attention in the daily and weekly press and at the meetings of vestries, county councils, railway directors, and others in authority that the grievance seems to be in a fair way of abolition. The Times, by opening its columns to the wail of those who have felt aggrieved by the latest device for the abstraction of the unwilling copper from female suffering humanity, namely, the penny-inthe-slot system, has done excellent service towards the abolition of that special impost, and the whole vicious principle on which it rests; for, why should females pay for an accommodation that is free to men? The London County Council, by recognising the right of each sex to public conveniences free of cost to the users and constructing plentiful number of the same in the most denselythronged thoroughfares of the metropolis, has conferred a boon on women which is in the highest degree worthy of imitation by other municipal authorities; and now that the Secretary of the London and South-Western Railway has promised, on behalf of his directors, that the objectionable penny-in-the-slot system shall be abolished at the stations of that improving railway, it is much to be desired that other boards of directors will see their way to a prompt decision in the same direction. A calm perusal by each director of the recent public correspondence on the subject, in which the inconvenience of present arrangements - often entailing positive cruelty on unwary females -was well portrayed, would probably lead to a complete abolition, not only of the slot device, but also of the whole system of compulsory payment by women. The withdrawing rooms must of course have caretakers or they would become unfit for use. Let the directors, if they fear the expense of retaining these attendants, permit voluntary contributions from the well-to-do, and there is no reason to fear that the shareholders would then be called upon to bear any of the expense incurred for the attendants' wages. The present arrangement, at any rate, is a very real and pressing grievance, and need only be dispassionately considered to meet with the prompt condemnation of all right thinking men and women.

(BMF 1892;ii;:703) 